\title{
A method to monitor the national salt reduction efforts in Sri Lanka and status of salt, potassium and iodine intake in an adult Sri Lankan community
}

\author{
R Jayatissa ${ }^{1 *}$, JA Santos ${ }^{2}$, RP Rannan-Eliya ${ }^{3}$, K Trieu ${ }^{2}$, AG Perera ${ }^{1}$, N De Alwis ${ }^{1}$, S Ranasingha ${ }^{1}$, \\ R Jayawardana ${ }^{1}$ and KH De Silva ${ }^{1}$ \\ ${ }^{1}$ Medical Research Institute, Sir Danister de Silva Mawatha, Colombo 08. \\ ${ }^{2}$ The George Institute for Global Health, PO Box M201, Missenden Rd, NSW 2050 Australia. \\ ${ }^{3}$ Institute of Health Policy, 72 Park Street, Colombo 02.
}

\begin{abstract}
Sri Lanka has initiated a salt reduction strategy in 2019 to reduce salt consumption to $8 \mathrm{~g}$ /day by 2025 . Recent national level salt consumption data is lacking. Although 24hour urine (24-hU) collection is the gold standard to assess salt intake, an alternative easy option for monitoring population salt consumption is needed. Objectives of this study were to assess the current salt, potassium, and iodine intake of adults based on 24-hU, and identify the best prediction equation to estimate these nutrients from spot urine (SU) samples. A crosssectional study was conducted among adults between 25-64 years of age. 24-hU and SU samples were collected. Several equations were used to estimate salt, potassium, and iodine from SU samples. The agreement between the estimates from 24-hU and SU was assessed through Bland-Altman plots and intraclass correlation coefficients. Among 852 adults recruited, 629 provided complete 24-hU. Measured 24-hU salt, potassium and iodine were: 11.4 (IQR 7.7-17.1) g, 2.1 (95\% CI 1.9-2.2) g and 209.8 (IQR 130.9-310.9) $\mu \mathrm{g}$, respectively. Comparison of estimates from 24-hU and SU samples showed that Kawasaki equation provided the closest estimate for salt intake [median bias -0.4(5.2-4.0) g; ICC 0.39; misclassification $13.6 \%$ ]; the equations used to estimate potassium intake performed poorly; while the Zimmerman equation provided the closest estimate for iodine [median bias -13.2 (-129.8-92.7) $\mu \mathrm{g}$; ICC 0.33; misclassification $37.2 \%$ ]. The adult population studied in Sri Lanka had high salt, low potassium, and optimum iodine intakes compared to the WHO recommendations. Collection of 24-hU in a subset of SU samples will be important to monitor the salt reduction efforts.
\end{abstract}

Keywords: 24-hour urine, iodine, potassium, salt, spot urine.

\section{INTRODUCTION}

Reduction of salt intake at the population level is considered as a public health 'best buy' by the World Health Organisation (WHO, 2017a). It is considered as a feasible and cost-effective public health initiative in preventing disabilities and deaths due to cardiovascular disease (CVD) and stroke (WHO, 2017b). It is wellestablished that high salt intake is a major contributor to hypertension (Elliott et al., 1996; He et al., 2013), which in turn contributes to CVD and stroke worldwide (WHO, 2010). In response to that, the WHO has established a global goal to reduce the intake of salt by $30 \%$ towards $5 \mathrm{~g}$ per day. This goal is part of the nine global targets to reduce the burden of non-communicable diseases (NCDs) by $25 \%$ by 2025 (WHO, 2010; 2013).

Approximately 40 percent of deaths in Sri Lanka is due to major NCDs such as ischaemic heart disease (IHD), neoplasms, etc. IHD has been the leading cause of death during recent decades in Sri Lanka $(\mathrm{MoH}$, 2020). On the other hand, available data from Sri Lankan national surveys in 1970 and 2015 indicated that the mean per capita salt consumption at the household

\footnotetext{
*Corresponding author (renukajayatissa@ymail.com; (D) https://orcid.org/0000-0002-3961-8735)
} 
level was 7 and $12 \mathrm{~g} /$ day, respectively (Mahadeva \& Karunanayake, 1970; Jayatissa et al., 2017), indicating a large increase in per capita salt consumption in the last 45 years. Recent sub-national studies of salt intake in Sri Lanka using 24-hU reported mean salt intakes of 8.8 $\mathrm{g} /$ day in 2012 (Jayatissa et al., 2020) and $12.4 \mathrm{~g} /$ day in 2016 (Gamage et al., 2017). To address the increasing salt intake in the Sri Lankan population and to reduce the burden of NCDs associated with high salt intake, a salt reduction policy was initiated in 2018 , and the strategic framework was developed by the Ministry of Health to reduce salt intake to $8 \mathrm{~g}$ per day by $2025(\mathrm{MoH}, 2018)$. To monitor the progress of this strategy, it is important to measure the current salt intake in the Sri Lankan population. Measurement of potassium and iodine intake along with salt intake are important in this context. Low intake of potassium is associated with hypertension, stroke and may increase the risk of mortality from CVD (Umesawa et al., 2008). The national iodine programme also relies on salt as a carrier of iodine (Campbell et al., 2012).

The best estimate of mean population salt intake is provided by measuring 24-hour urinary sodium (24-hUNa) excretion in a representative sample of individuals (WHO, 2018). However, 24-hU collection is labour-intensive, costly and imposes a high burden on participants, especially in the context of population surveys. There has been much interest in using spot urine (SU) sodium measurements as a replacement for 24-hU collection (PAHO, 2010). There are several equations which have been tested in many countries to calculate salt intake from SU samples (Kawasaki et al., 1993; Tanaka et al., 2002; Mage et al., 2008; Brown et al., 2013; Whitton et al., 2016; Santos et al., 2019; Xu et al., 2020), but these equations have not been evaluated in the Sri Lankan population.

Hence, the objectives of this study were to measure the sodium, potassium and iodine intake among adults aged 25-64 years in Sri Lanka based on 24-hU, and to test the usefulness of SU samples to estimate these nutrients.

\section{METHODOLOGY}

A population-based cross-sectional study was conducted between January to July 2019 among adults aged 2564 years. Calculated sample size was 120 people per stratum considering $1 \mathrm{~g}$ reduction in salt intake over time using 24-hUNa, with the standard deviation of $75 \mathrm{mmol} /$ day $($ alpha $=0.05$, power $=0.80)$. Age $(24-44 / 45-64$ years), sex (male/female), and sector (urban/rural) were taken as sub-groups, giving a total of six strata (PAHO, 2010). A response rate of $60 \%$ was taken considering non-participation, incomplete collection due to spillage, missed voids or overcollection (beyond 24-h) and implausible values. An adjusted sample size was 900 .

\section{Study settings and sampling}

A multi-stage stratified cluster sampling design was used to select a population-based sample. Participants who were pregnant, lactating and menstruating at the time of the study were excluded. Grama-Niladari Divisions (GND), which are the smallest administrative units, were identified as clusters. Ninety GND (20\% from the urban sector based on population proportion) were selected using probability proportional to population size, listing all GND in the country with the population. For each GND, 10 households were randomly selected using the 2016 electoral register, and one individual was randomly selected from each household.

\section{Data collection}

Ethical approval was obtained from the Ethics Committee of the Medical Research Institute (Number: 15/2017). After explaining the aims of the study and obtaining written informed consent, the research team interviewed the participants using the pre-tested questionnaire. Participant's height, weight, and blood pressure (two times) were measured adopting the WHO protocol $(\mathrm{MoH}, 2018)$. Each participant was asked to collect urine over a 24-h period and one SU sample after discarding the first urine sample in the morning on the first day. Participants were provided with detailed verbal and written instructions along with equipment for collecting urine samples adopting the WHO guide (WHO, 2018). Field investigators recorded the volume of each void, start and finish times of the 24-hU collection and the time of the spot urine collection. Upon picking-up completed urine samples, participants were asked about any missed voids or spillage and asked to complete the 24-hU collection again if any urine voids were missed or spilled. Field investigators measured the volume of the urine samples prior to sending to the laboratory and stored at $-20^{\circ} \mathrm{C}$ till analysis.

Urinary sodium and potassium were determined using the ion-selective electrode method. The buffered kinetic Jaffe reaction without deproteinization was used for urine creatinine assay. Internal quality control (QC) was performed using commercially prepared QC samples 
(Bio-rad, level 1 and 2) for three analytes separately. It was run on the analyser for correct calibration and function before the samples were analysed and included in every batch to determine between-assay precision. Urine iodine was measured by ammonium persulfate digestion with spectrophotometric detection of the Sandell-Kolthoff reaction in a laboratory certified by the EQUIP programme. Body mass index (BMI) was calculated using weight $(\mathrm{kg}) /$ height $^{2}$ (meters).

To maintain the accuracy of 24-hU samples, the following samples were excluded from the final analysis based on the following established criteria; total urine volume was $<500 \mathrm{~mL}$ or total creatinine excretion of women was $<4 \mathrm{mmol} /$ day or $>25 \mathrm{mmol} /$ day, and men was $<6 \mathrm{mmol} /$ day or $>30 \mathrm{mmol} /$ day. In addition, spot urine samples were excluded based on the following criteria: creatinine concertation was $<1.8 \mathrm{mmol} / \mathrm{L}$ for both sexes, or $>28.3 \mathrm{mmol} / \mathrm{L}$ for women and $>32.7 \mathrm{mg} / \mathrm{L}$ for men (Santos et al., 2019).
$24 \mathrm{hUNa}$ and potassium concentrations $(\mathrm{mmol} / \mathrm{L})$ were multiplied by the urine volume (L), to obtain 24hUNa and potassium excretion (mmol/day). Sodium in $\mathrm{mmol} /$ day was converted to salt in grams by dividing by 17.1. Potassium in $\mathrm{mmol} /$ day was converted to $\mathrm{mg}$ by dividing by 39.1 .

To estimate 24-hNa excretion estimates from SU samples, five equations (Intersalt with or without potassium, Kawasaki, Tanaka, Mage) were used for sodium; (Kawasaki et al., 1993; Tanaka et al., 2002; Mage et al., 2008; Brown et al., 2013; Santos et al., 2019) three equations (Kawasaki, Tanaka and Mage) were used for potassium; (Kawasaki et al., 1993; Tanaka et al., 2002; Mage et al., 2008; Brown et al., 2013) and two equations (Zimmerman and IOM) were used for iodine (Zimmerman \& Andersson, 2012; IOM, 2001). Predicted 24-h creatinine clearance was calculated using the Johner equation for the Zimmerman equation (Johner et al., 2015). The equations are presented below.

Spot equations to estimate 24-hour sodium excretion (mmol/day)

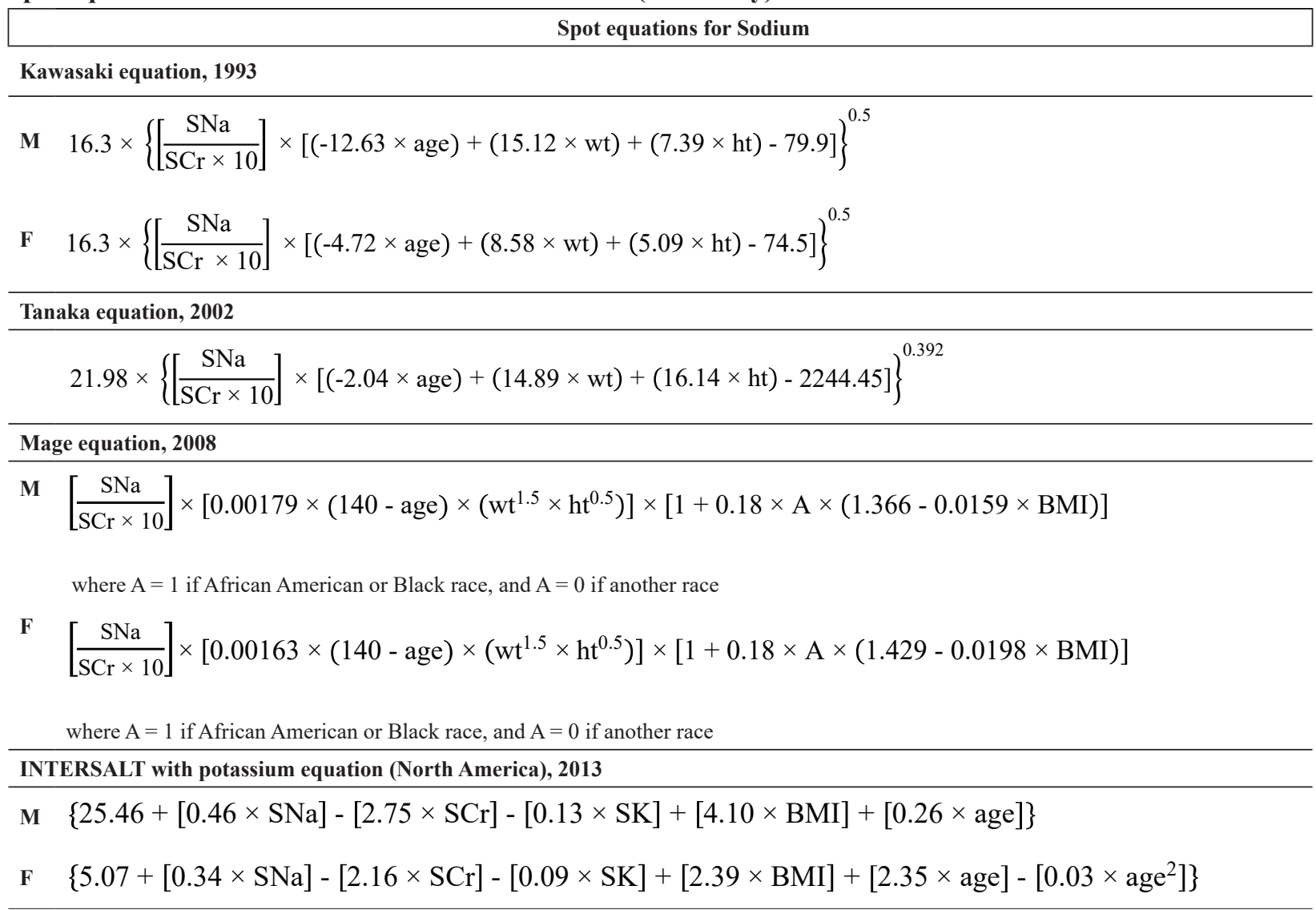




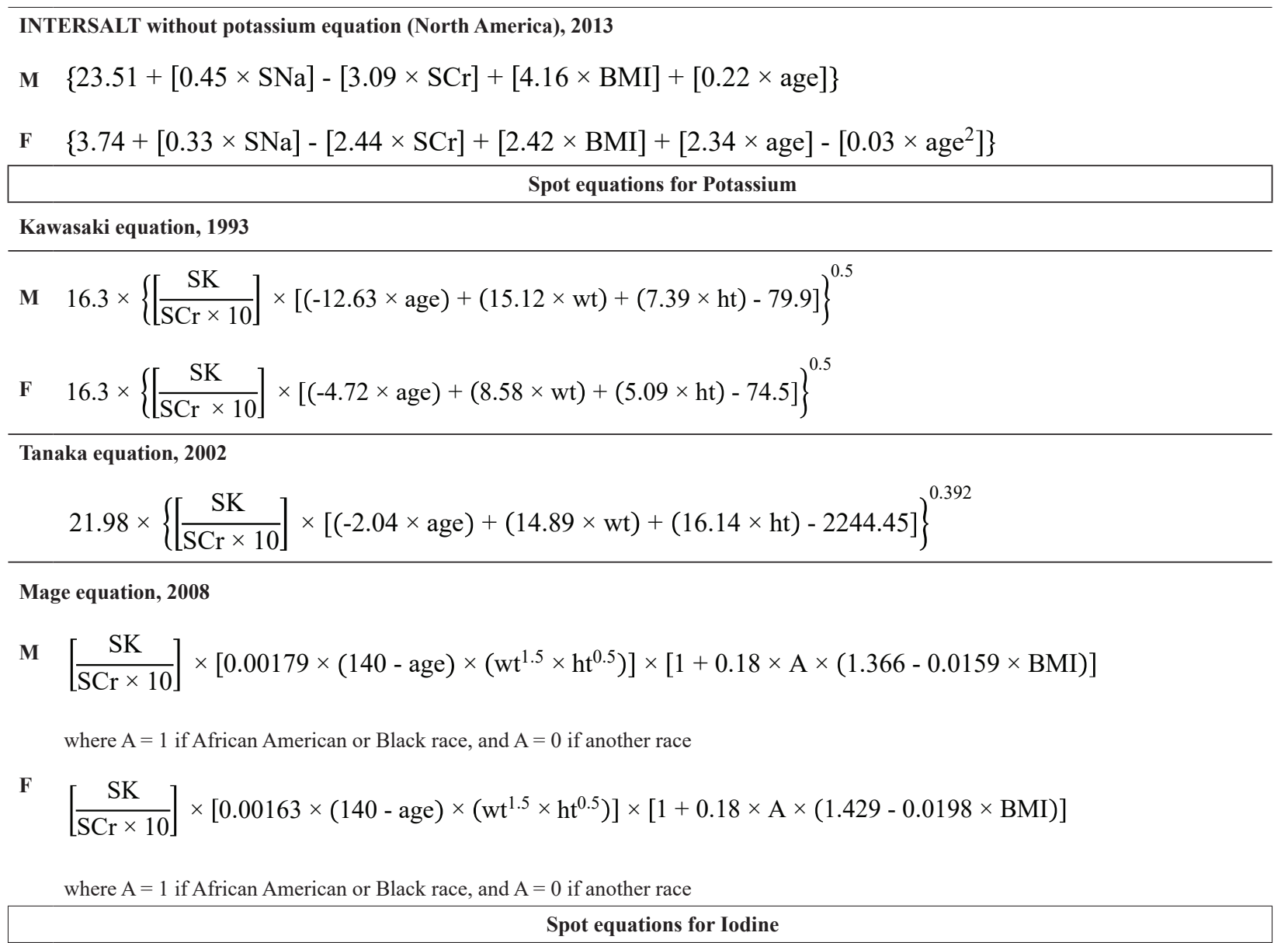

IOM equation (IOM, 2001)

daily iodine intake $=(\mathrm{SI} \mathrm{g} / \mathrm{L}) \div 0.92 \times(0.0009 \mathrm{~L} / \mathrm{hour} / \mathrm{kg} \times 24-\mathrm{h} /$ day $) \times$ weight $\mathrm{kg}$

Zimmerman equation (Zimmerman, 2012)

$\left[\frac{\mathrm{SI} \mathrm{g} / \mathrm{L}}{\mathrm{SCr} \mathrm{mmol} / \mathrm{L}}\right] \times[24-\mathrm{h}$ Reference Creatinine clearance $(\mathrm{mmol})] \mathrm{m}^{2}$

Prediction equation: 24-h Creatinine excretion ( $\mathrm{mmol}$ per day) $=$

$\mathrm{E}^{[1.9539+0.1681 \times \text { sex }-0.0027 \times \text { age }(\text { years })+0.0129 \times \text { weight }(\mathrm{kg})-0.0129 \times \mathrm{BMI}(\mathrm{kg} / \mathrm{m} 2)]}$

$\overline{(\mathrm{SNa}}=$ spot sodium; $\mathrm{SCr}=$ spot creatinine; $\mathrm{SK}=$ spot potassium; $\mathrm{SI}=$ spot iodine; $\mathrm{ht}=$ height; $\mathrm{wt}=$ weight; $\mathrm{BMI}=$ body mass index; $\mathrm{SNa}$ in $\mathrm{mmol} / \mathrm{L}$; $\mathrm{SK}$ in $\mathrm{mmol} / \mathrm{L}$; $\mathrm{SCr}$ in $\mathrm{mmol} / \mathrm{L}$ for the INTERSALT equations, in $\mathrm{mg} / \mathrm{dL}$ for the other four equations; age in years; weights in kilograms; height in centimetres; BMI in $\mathrm{kg} / \mathrm{m}^{2}$ )

\section{Data analysis}

Analysis was performed using SPSS (IBM version 24) and Stata 14 for Windows (StataCorp, College Station, TX, USA). Data were expressed as mean (SD/Confidence Interval-CI) or as median (IQR) for continuous variables, and as proportion for categorical variables. The ShapiroWilk test was used to test for normality. Kruskal-Wallis and ANOVA tests were used to compare groups. To compare the estimates from 24-h and SU samples, the tests used were: (1) paired Wilcoxon signed rank test for median salt and iodine, and paired samples t-test was used for mean salt and mean potassium to determine the differences between the two methods; (2) misclassification of each of the equations were calculated to determine their ability to correctly classify participants according to the reference values of sodium (5g), (WHO, 2012a) potassium (3.5 g) (WHO, 2012b) and iodine (150 $\mu \mathrm{g})$ (UNICEF, 2019); and (3) BlandAltman plots and intraclass correlation coefficients (ICC) 
were used to assess the agreement between 24-hU and SU samples.

\section{RESULTS AND DISCUSSION}

\section{Participant characteristics}

This study provided nationally representative 24-hU estimates of dietary salt, potassium, and iodine intake among Sri Lankan adults aged 25-64 years, to support the national salt reduction strategy 2018-2022 (MoH, 2020). A total of 629 (69.8\% of the sample) participants were included in the final analysis, after 48 of 900 invited participants refused to participate and a further 223 urine collections were excluded based on the established criteria for suspected inaccurate $24-\mathrm{hU}$ and SU collection. Overall, $55.2 \%$ of urine samples were collected on a weekday, and $44.8 \%$ were collected on a weekend. Approximately $85 \%$ of SU samples were collected in the morning.

The mean age of the participants was 46 years and $54.5 \%$ were females. Majority were Sinhalese (78.1 \%), belonged to Buddhist religion (73.8 \%), from rural residency $(79.7 \%)$ and educated more than grade $11(56.6 \%)$. The composition of the study sample in relation to the ethnicity, religion and area of residence is comparable to the profile of the national population (CBS, 2019). The average BMI was $25 \mathrm{~kg} / \mathrm{m}^{2}$, and the mean systolic and diastolic blood pressure (SBP and DBP) was 122 and $79 \mathrm{mmHg}$, respectively. Average 24-hU volume was $2.2 \mathrm{~L} /$ day and creatinine concentration was $11.9 \mathrm{mmol} / \mathrm{L}$. Average voids per day was 7.5 times, and the average volume of each void was $0.26 \mathrm{~L}$ (Table 1).

\section{Salt intake estimates}

Table 2 shows that there was a wide distribution in measured 24-h salt intake. This makes the median a more robust description of the salt intake of overall population. The measured median and mean salt intake for adults aged 25-64 years was 11.4 (IQR 7.7-17.1) and 13.3 (CI 12.5-14.1) g/day respectively, which is higher than the value reported in previous studies in Sri Lanka (Gamage et al., 2017; Jayatissa et al., 2020) as well as higher than other countries (Jianwei et al., 2014; Mill et al., 2015; Huang et al., 2016; Santos et al., 2019; Xu et al., 2020). Salt intake among men was significantly higher than women $(12.5$ vs. $10.4 \mathrm{~g} /$ day; $\mathrm{p}<0.001)$ as shown in other studies (Huang et al., 2016; Whitton et al., 2016; Santos et al., 2019; Xu et al., 2020). There was no difference in median salt intake between groups, apart from education $(\mathrm{p}=0.004)$. Overall, $88.4 \%$ of the participants had higher salt intake than the WHO recommended $<5 \mathrm{~g}$ /day (WHO, 2012a).

Table 1: $\quad$ Basic information of the study population $(n=629)$

\begin{tabular}{|c|c|}
\hline Background information & Percentage \\
\hline \multicolumn{2}{|l|}{ Sex } \\
\hline Male & 45.5 \\
\hline Female & 54.5 \\
\hline \multicolumn{2}{|l|}{ Area of residence } \\
\hline Urban & 20.3 \\
\hline Rural & 79.7 \\
\hline \multicolumn{2}{|l|}{ Education } \\
\hline No formal & 2.2 \\
\hline Primary (1-5 grade) & 8.8 \\
\hline Secondary (6-11 grade) & 32.4 \\
\hline Higher (> 11 grade) & 56.6 \\
\hline \multicolumn{2}{|l|}{ Ethnicity } \\
\hline Sinhala & 78.1 \\
\hline Tamil & 16.2 \\
\hline Muslim/Other & 5.7 \\
\hline \multicolumn{2}{|l|}{ Religion } \\
\hline Buddhist & 73.8 \\
\hline Hindu & 13.0 \\
\hline Christian & 8.4 \\
\hline Islam & 4.8 \\
\hline \multicolumn{2}{|l|}{ BMI categories $\left(\mathrm{kg} / \mathrm{m}^{2}\right)$} \\
\hline$<25.0$ & 57.4 \\
\hline $25.0-29.9$ & 31.3 \\
\hline$\geq 30.0$ & 11.3 \\
\hline \multicolumn{2}{|l|}{ Blood pressure groups } \\
\hline $\mathrm{SBP} \leq 140$ or $\mathrm{DBP} \leq 90$ & 79.0 \\
\hline \multirow[t]{2}{*}{$\mathrm{SBP}>140$ or $\mathrm{DBP}>90$} & 21.0 \\
\hline & Mean (SD) \\
\hline Age, years & $45.9(10.6)$ \\
\hline Height, cm & $159.1(8.7)$ \\
\hline Weight, kg & $62.2(11.8)$ \\
\hline BMI, $\mathrm{kg} / \mathrm{m}^{2}$ & $24.6(4.5)$ \\
\hline Systolic Blood Pressure (SBP), mmHg & $122.3(17.0)$ \\
\hline Diastolic Blood Pressure (DBP), $\mathrm{mmHg}$ & $78.8(11.0)$ \\
\hline 24-h urine volume, $\mathrm{L}$ & $2.2(1.1)$ \\
\hline Creatinine concentration, $\mathrm{mmol} / \mathrm{L}$ & $11.9(4.8)$ \\
\hline Number of times void urine per day & $7.5(2.5)$ \\
\hline Urine volume of each void, L & $0.26(0.1)$ \\
\hline
\end{tabular}


Table 2: $\quad$ Measured 24-h salt (g/day), potassium (g/day) and iodine ( $\mu \mathrm{g} /$ day) intake in relation to basic information and compared to WHO recommendation ${ }^{\text {b }}$

\begin{tabular}{|c|c|c|c|}
\hline Basic information & Salt intake median (IQR) & $\begin{array}{c}\mathrm{K} \text { intake mean } \\
(\mathrm{SD})\end{array}$ & Iodine intake median (IQR) \\
\hline \multicolumn{4}{|l|}{ Age groups } \\
\hline $25-44$ & $11.7(7.3-16.6)$ & $2.0(1.7)$ & $213.1(130.0-324.4)$ \\
\hline $45-64$ & $11.3(7.7-17.1)$ & $2.2(2.0)$ & $209.0(131.0-299.6)$ \\
\hline \multicolumn{4}{|l|}{ Sex } \\
\hline Female & ${ }^{\mathrm{a}} 10.4(6.7-15.4)$ & a $1.9(1.7)$ & a197.6 (111.4-279.7) \\
\hline Male & $12.5(8.3-17.7)$ & $2.3(2.0)$ & $239.1(143.5-351.4)$ \\
\hline \multicolumn{4}{|l|}{ Sector } \\
\hline Urban & $11.6(7.8-17.3)$ & $2.3(2.2)$ & $216.9(129.8-338.7)$ \\
\hline Rural & $11.1(7.2-16.3)$ & $2.0(1.7)$ & $207.8(130.9-300.9)$ \\
\hline \multicolumn{4}{|l|}{ Ethnicity } \\
\hline Sinhalese & $11.3(7.2-17.1)$ & $2.1(1.7)$ & $209.1(132.7-310.9)$ \\
\hline Tamil & $11.5(7.7-15.2)$ & $2.0(2.1)$ & $215.0(122.0-310.9)$ \\
\hline Muslim & $9.8(7.8-13.3)$ & $2.5(2.4)$ & $212.8(98.1-296.4)$ \\
\hline \multicolumn{4}{|l|}{ Religion } \\
\hline Buddhist & $11.3(7.2-16.9)$ & $2.1(1.8)$ & $211.5(133.4-314.1)$ \\
\hline Hindu & $11.8(7.9-15.9)$ & $2.2(2.3)$ & $207.7(120.1-356.3)$ \\
\hline Catholic/Christian & $10.4(6.6-17.3)$ & $1.6(1.1)$ & $209.0(126.8-286.6)$ \\
\hline Islam & $9.2(7.7-13.0)$ & $2.3(2.6)$ & $180.9(94.4-293.5)$ \\
\hline \multicolumn{4}{|l|}{ Education (grade) } \\
\hline No formal & a $7.2(4.4-10.1)$ & $2.1(1.8)$ & $155.0(131.9-266.4)$ \\
\hline Primary (1-5) & $9.5(7.7-13.5)$ & $2.2(2.5)$ & $217.3(108.6-293.5)$ \\
\hline Secondary (6-11) & $12.5(8.0-17.6)$ & $2.0(1.9)$ & $221.5(133.9-342.7)$ \\
\hline Higher $(>11)$ & $11.3(7.0-16.6)$ & $1.9(1.7)$ & $204.4(129.9-294.8)$ \\
\hline \multicolumn{4}{|l|}{ BMI categories } \\
\hline$<25$ & $10.6(7.2-15.6)$ & a $2.1(1.9)$ & $273.9(130.7-308.7)$ \\
\hline $25-29.9$ & $12.4(7.5-17.7)$ & $1.9(1.4)$ & $198.3(128.7-306.6)$ \\
\hline$>30$ & $11.3(7.6-16.3)$ & $2.6(2.4)$ & $230.2(145.7-369.4)$ \\
\hline \multicolumn{4}{|l|}{ Systolic BP (SBP) } \\
\hline $\mathrm{SBP} \leq 140$ & $11.2(7.2-16.6)$ & $2.1(1.8)$ & $207.7(130.1-323.3)$ \\
\hline $\mathrm{SBP}>140$ & $11.7(8.2-16.9)$ & $2.2(1.9)$ & $214.6(135.2-302.5)$ \\
\hline \multicolumn{4}{|l|}{ Diastolic BP (DBP) } \\
\hline $\mathrm{DBP} \leq 90$ & $11.3(7.5-16.7)$ & $2.1(1.8)$ & $207.3(129.4-323.5)$ \\
\hline $\mathrm{DBP}>90$ & $10.9(7.2-16.3)$ & $2.1(2.0)$ & $214.6(141.4-294.7)$ \\
\hline \multicolumn{4}{|l|}{ Between BP groups } \\
\hline Normotensive & $11.2(7.2-16.6)$ & $2.1(1.8)$ & $206.7(129.9-323.2)$ \\
\hline \multicolumn{4}{|l|}{$\mathrm{SBP} \leq 140$ or $\mathrm{DBP} \leq 90$} \\
\hline Hypertensive & $11.5(7.8-16.9)$ & $2.2(2.0)$ & $214.8(135.9-311.0)$ \\
\hline \multicolumn{4}{|l|}{$\mathrm{SBP}>140$ or $\mathrm{DBP}>90$} \\
\hline Overall & $11.4(7.7-17.1)$ & $2.1(1.9)$ & $209.8(130.9-310.9)$ \\
\hline $\begin{array}{l}\text { Percentage above the WHO } \\
\text { recommendations }^{\mathrm{b}}\end{array}$ & 88.4 & 84 & 29.6 \\
\hline
\end{tabular}

${ }^{a} \mathrm{p}<0.05$

${ }^{b}(88.4 \%, 84 \%$ and $29.6 \%$ of study population had a higher intake of salt, potassium and iodine than the WHO recommended intakes of $5 \mathrm{~g}, 3.5 \mathrm{~g}$ and $150 \mu \mathrm{g}$, respectively) 
As shown in Table 3, this study also assessed whether previously published and commonly used equations could be used to estimate daily salt intake using SU samples. This is important to monitor the goal of the country's salt reduction programme, given the challenges and difficulties associated with collecting 24-hU samples (WHO, 2018; PAHO, 2010). Pairwise comparisons of salt intakes based on 24-h versus SU samples showed that the five equations underestimated the mean and median salt intake of the adult population studied (Table 3). This could be due to the fact that the salt intake measured from $24-\mathrm{hU}$ is high, and these spotbased equations tend to underestimate population salt intake when the actual consumption is high as shown in a previous systematic review and meta-analysis (huang et al., 2016).

Table 3: 24-h salt, potassium and iodine intake measured from 24-hU samples and estimated based on equations using spot urine

\begin{tabular}{|c|c|c|c|c|}
\hline \multirow[t]{2}{*}{ Measurement } & \multicolumn{4}{|c|}{ 24-h intake } \\
\hline & Salt Median (IQR) & Salt Mean (CI) & Potassium Mean (CI) & Iodine Median (IQR) \\
\hline 24-h measured & $\begin{array}{c}11.4 \\
(7.7-17.1)\end{array}$ & $\begin{array}{c}13.3 \\
(12.5-14.1)\end{array}$ & $\begin{array}{c}2.1 \\
(1.9-2.2)\end{array}$ & $\begin{array}{c}209.8 \\
(130.9-310.9)\end{array}$ \\
\hline \multicolumn{5}{|c|}{ Equations for spot samples } \\
\hline Intersalt with $\mathrm{K}$ & $\begin{array}{c}\text { a } 7.6 \\
(6.6-9.0)\end{array}$ & $\begin{array}{c}\text { a } 7.9 \\
(7.7-8.0)\end{array}$ & - & - \\
\hline Intersalt without $\mathrm{K}$ & $\begin{array}{c}\text { a } 7.5 \\
(6.5-8.8)\end{array}$ & $\begin{array}{c}\text { a } 7.7 \\
(7.6-7.9)\end{array}$ & - & - \\
\hline Tanaka & $\begin{array}{c}{ }^{\text {a }} 8.7 \\
(6.9-10.5)\end{array}$ & $\begin{array}{c}{ }^{\mathrm{a}} 12.0 \\
(11.7-12.4)\end{array}$ & $\begin{array}{c}\text { a } 3.0 \\
(2.9-3.1)\end{array}$ & - \\
\hline Kawasaki & $\begin{array}{c}11.2 \\
(8.5-14.3)\end{array}$ & $\begin{array}{c}\text { a } 9.0 \\
(8.8-9.2)\end{array}$ & $\begin{array}{c}\text { a } 3.3 \\
(3.2-3.4)\end{array}$ & - \\
\hline Mage & $\begin{array}{c}{ }^{\text {a }} 6.5 \\
(3.5-10.5)\end{array}$ & $\begin{array}{c}{ }^{\text {a }} 8.8 \\
(8.2-9.5)\end{array}$ & $\begin{array}{c}{ }^{\text {a }} 6.4 \\
(5.9-7.0)\end{array}$ & - \\
\hline $\begin{array}{l}\text { Institute of Medicine } \\
\text { (IOM) }\end{array}$ & - & & - & $\begin{array}{c}{ }^{\mathrm{b}} 140.2 \\
(85.5-211.8)\end{array}$ \\
\hline Zimmerman & - & & - & $\begin{array}{c}{ }^{\mathrm{b}} 174.0 \\
(90.3-323.8)\end{array}$ \\
\hline
\end{tabular}

${ }^{\mathrm{a}} \mathrm{p}=0.001 ;{ }^{\mathrm{b}} \mathrm{p}=<0.001$; Wilcoxon signed rank test for median and paired t-test for mean

In this study, the degree of bias was considerable for all the five equations (Table 4), but smallest with the Kawasaki equation (median difference of $-0.4 \mathrm{~g}$ ) as shown with previous work in Asia, Fiji and Samoa (Huang et al., 2016; Santos et al., 2019; Xu et al., 2020). Although the 24-hu and SU samples were collected from the same individuals on the same day, the intraclass correlation between measured and estimated 24-hUNa excretion was low (ICC ranged from 0.27 to 0.43 ), indicating poor reliability of the estimates from SUs. In terms of ICC, the Mage and Kawasaki equation produced the highest ICCs, showing poor to moderate reliability. Similar findings have been reported by studies in China, UK, Italy, Fiji and Samoa confirming that SU assays cannot be relied on in most populations for estimating the level of intake at the individual level (Huang et al., 2016; Santos et al., 2019).
On the other hand, in terms of classifying salt intake as above or below the WHO recommended limit of $5 \mathrm{~g}$ per day, findings of the present study show that the equations (apart from Mage) only misclassified about 12-14\% of the sample-indicating the ability of SU to classify salt intake as above or below $5 \mathrm{~g}$, as shown in a previous meta-analysis (huang et al., 2016). The 12-14\% misclassification error is small in relation to the high percentage $(88 \%)$ of sample that had a high salt intake. The results also imply that the percentage error would be even smaller as average salt intake levels reduce closer to the WHO recommended levels.

Based on the Bland-Altman plots (Figure 1), the presence of proportional bias was evident for the Intersalt with $\mathrm{K}$, Intersalt without $\mathrm{K}$ and the Tanaka equation (Figure 1.1). For these equations, SU samples 
Table 4: Comparison between 24-h salt, potassium and iodine intake measured in 24-hU samples and estimated in spot samples with the different equations

\begin{tabular}{lccc}
\hline Estimated 24-h intakes & $\begin{array}{c}\text { Median (IQR) } \\
\text { mean }(\mathrm{SD}) \text { difference } \\
(\mathrm{g} / \mu \mathrm{g})\end{array}$ & $\begin{array}{c}\text { ICC } \\
(95 \% \mathrm{CI})\end{array}$ & $\begin{array}{c}\text { Mis-classification } \\
\%\end{array}$ \\
\hline Salt & $\begin{array}{c}\text { Median } \\
\text { Intersalt with } \mathrm{K}\end{array}$ & $0.27(0.14$ to 0.37$)$ & 12.9 \\
Intersalt without $\mathrm{K}$ & $-3.4(-8.7-0.0)^{\mathrm{a}}$ & $0.27(0.14$ to 0.37$)$ & 13.8 \\
Tanaka & $-3.5(-8.8-0.1)^{\mathrm{a}}$ & $0.29(0.17$ to 0.39$)$ & 13.9 \\
Kawasaki & $-2.3(-8.1-1.2)^{\mathrm{a}}$ & $0.39(0.28$ to 0.48$)$ & 30.7 \\
Mage & $-0.4(-5.2-4.0)$ & $0.43(0.33$ to 0.51$)$ & 35.2 \\
Potassium & $-4.0(-9.3-0.3)^{\mathrm{a}}$ & & 41.6 \\
Tanaka & Mean & $0.07(-0.09$ to 0.21$)$ & 55.7 \\
Kawasaki & $+0.9(2.1)^{\mathrm{a}}$ & $0.08(-0.08$ to 0.21$)$ & \\
Mage & $+1.2(2.3)^{\mathrm{a}}$ & $-0.08(-0.27$ to 0.08$)$ & 43.3 \\
Iodine & $+4.3(7.0)^{\mathrm{a}}$ & & 37.2 \\
IOM & Median & $0.18(0.04$ to 0.30$)$ & \\
Zimmerman & $-59.1(-155.5-27.2)^{\mathrm{a}}$ & $0.33(0.21$ to 0.42$)$ & \\
\hline
\end{tabular}

${ }^{a} \mathrm{p}<0.05$; measured 24-hU iodine and potassium: $\mathrm{r}=0.2660 ; \mathrm{p}<0.001-$ significant weak correlation; Measured 24-hU iodine and sodium: $\mathrm{r}=0.1196 ; \mathrm{p}=0.003$ - significant weak correlation

overestimated salt intake at lower levels of consumption, and underestimated salt intake at higher levels of consumption. On the other hand, for the Kawasaki and Mage equations, wider limits of agreement were observed at higher levels of consumptions. However, it can be noted that the errors associated with the Intersalt and Tanaka equations as shown by the Bland-Altman plots (Figure 1.1) appear to be systematically related to the level of the target indicator and very similar in their linearity and gradients to that reported in studies from Fiji, Samoa and Brazil (Mill et al., 2015; Santos et al., 2019). This suggests that a similar reparameterization of all three equations could substantially improve their performance and reduce their bias and mean error for use in Sri Lanka and several other populations, and make them a better alternative to the Kawasaki equation.

\section{Potassium intake estimates}

24-hU collection is recommended to assess the daily potassium intake, since $77 \%$ of potassium intake in the previous $24-\mathrm{h}$ is excreted in the urine and $18 \%$ in stool (WHO, 2012b). The daily potassium intake using $24-\mathrm{hU}$ excretion was $2.1(1.9-2.2)$ g. Potassium intakes were below the recommended minimum levels required to lower blood pressure. Mean daily intake of potassium in males was significantly higher than females (2.3 vs. $1.9 \mathrm{~g} / \mathrm{day} ; \mathrm{p}=0.009$ ). There was no difference in mean potassium intake by age, residency, blood pressure, ethnicity and religion, apart from BMI $(\mathrm{p}=0.004)$. Approximately $84 \%$ of the participants had lower potassium intake than the WHO recommended $>3.5 \mathrm{~g} /$ day (Table 2).

Pairwise comparisons of potassium intakes based on 24-h versus SU samples showed that the three equations overestimated the mean potassium intake (Table 3). Although the Tanaka equation produced the closest potassium intake compared to $24-\mathrm{hU}$, this study suggests that the three equations performed poorly in terms of measuring potassium intake or classifying potassium intake as above or below the recommended limit.

The smallest mean difference $(0.9 \mathrm{~g})$ and the lowest misclassification $(35.2 \%)$ was shown by the Tanaka equation. In terms of ICC, the three equations showed poor reliability (Table 4).

Proportional bias was present for both the Tanaka and Mage equation, although the direction of bias was opposite for the two equations. For the Kawasaki equation, widening limits of agreement were noted with increasing potassium consumption (Figure 1.2). 
Salt
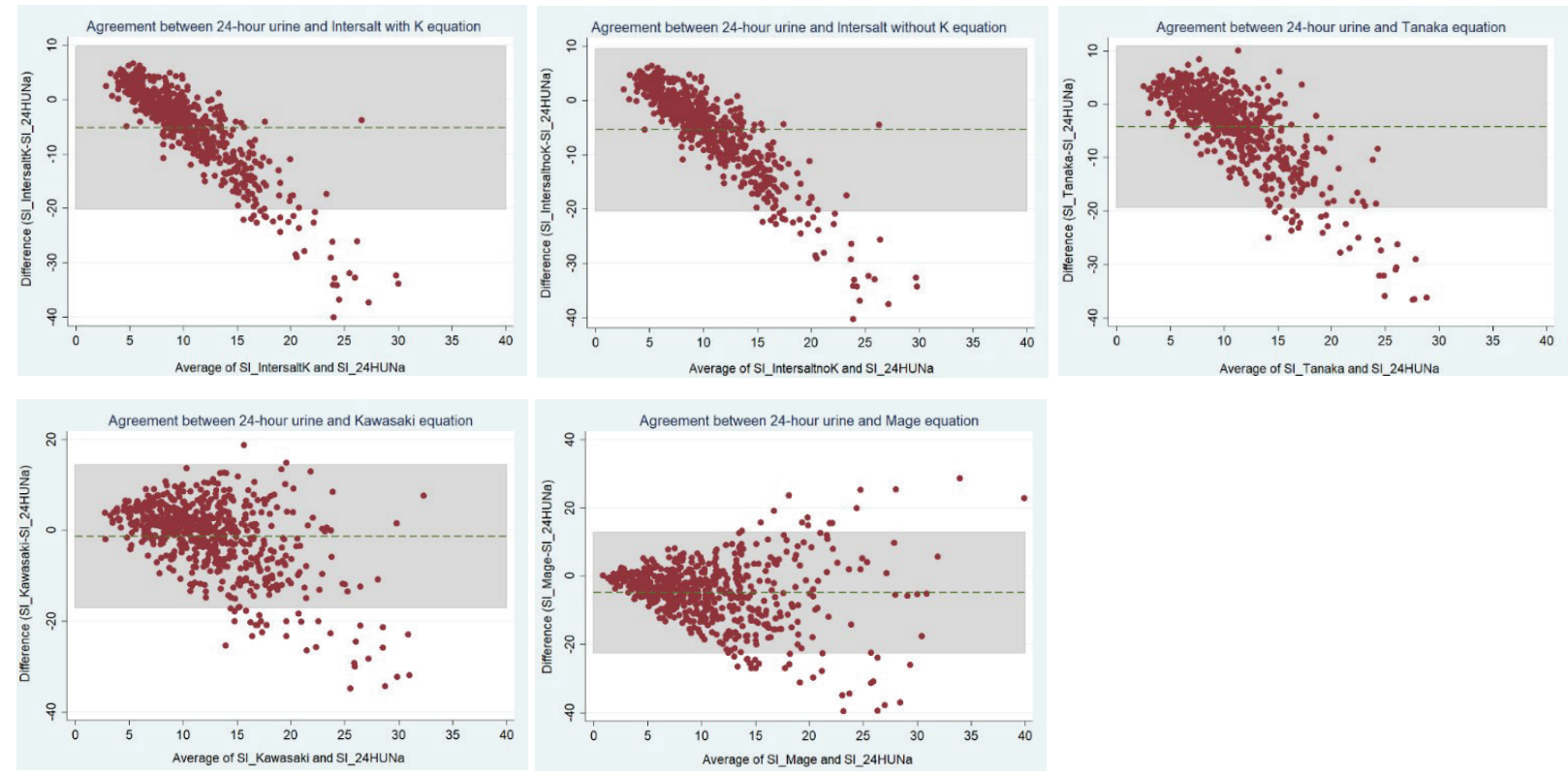

Potassium
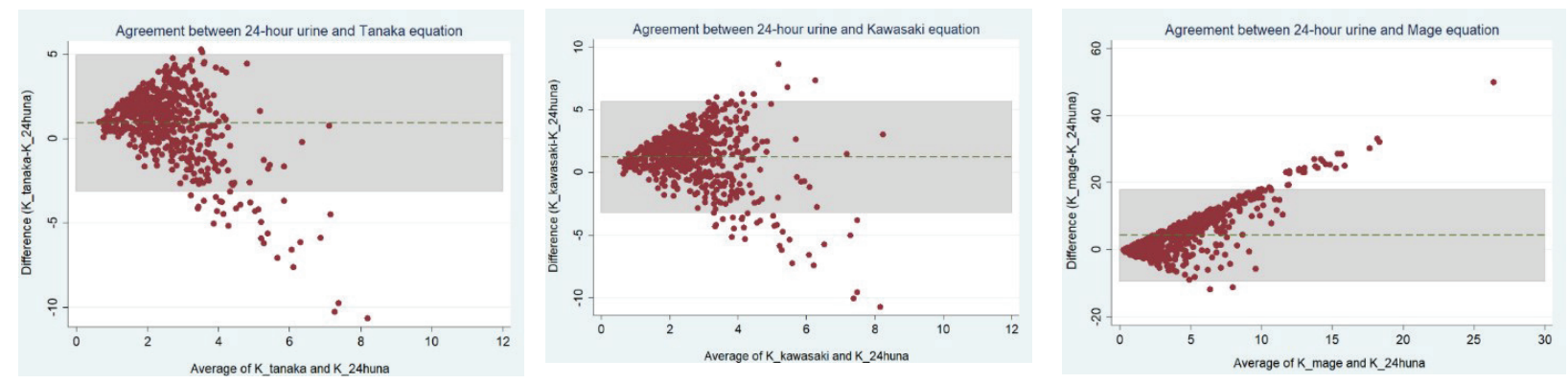

Iodine
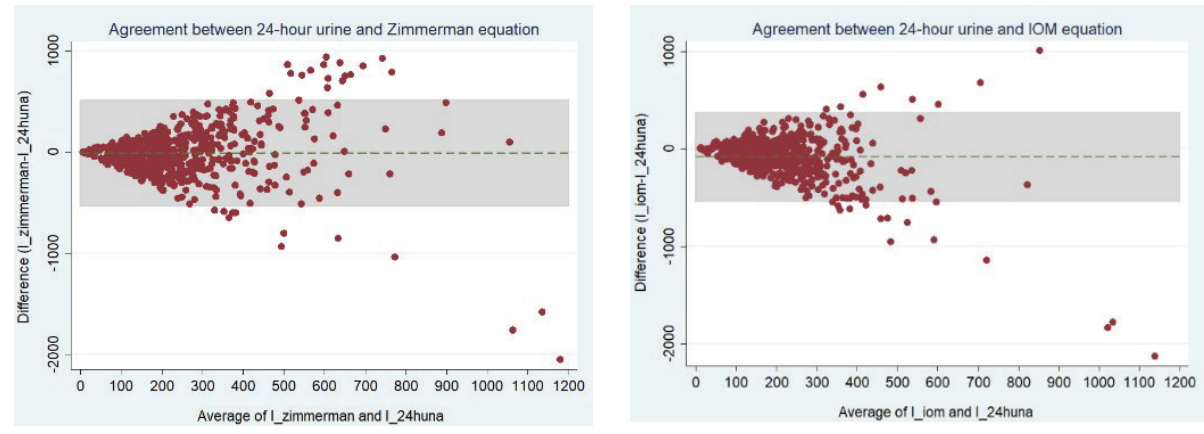

Figure 1: Bland-Altman plots of salt, potassium and iodine intake 


\section{Iodine intake estimates}

Casual SU samples are taken to estimate the urine iodine concentration to track the optimum iodine intake of the population (UNICEF, 2019). Over $90 \%$ of dietary iodine is excreted in the urine within $24-48 \mathrm{~h}$ by adults and relatively constant over the time of the day (IOM, 2001). The median concentration of iodine was 209.8 (130.9-310.9) $\mu \mathrm{g} / \mathrm{L}$ in the 24-hU samples. 24-hU iodine excretion showed the optimum iodine intake in this population. The daily intake of iodine in men was significantly higher than women (239.1 vs. $197.6 \mu \mathrm{g} /$ day; $\mathrm{p}<0.001)$. The measured 24-h iodine intake between age groups, residing in urban or rural areas, BMI categories, blood pressure groups, ethnic and religion groups did not show any differences. Overall, $29.6 \%$ of the participants had lower iodine intake than the WHO recommended $>150 \mu \mathrm{g} /$ day (Table 2).

As shown in Tables 3 and 4, available equations were used in this study and it indicated that the two equations underestimate the 24-hU iodine intakes (Zimmerman:174.0 and IOM:140.2 $\mu \mathrm{g}$ ) compared to measured (24-h: $209.8 \mu \mathrm{g})$. Previous studies have reported similar findings (Perrine et al., 2014; Charlton et al., 2018). The best 24-hU iodine estimates were obtained with the Zimmerman equation (median bias: $-13.2 \mu \mathrm{g}$, ICC: 0.33 , and misclassification: $37.2 \%$ ). For both equations, proportional bias was not present, but widening limits of agreement with increasing iodine consumption were observed (Figure 1.3).

\section{Iodine vs. sodium and potassium}

In this study, the relationship between salt vs. iodine and iodine vs. Potassium was examined to assess the effect of salt reduction on iodine intake and the contribution of potassium iodide in salt to potassium intake. Correlation between measured 24-hU iodine vs sodium ( $\mathrm{r}=0.1$; $\mathrm{p}<0.003)$ and iodine vs potassium $(\mathrm{r}=0.3 ; \mathrm{p}<0.001)$ shows weak correlation (Table 4 ), indicating that salt might not be the main source of iodine compared to contributions by other iodine sources such as drinking water, as highlighted in a previous study (Jayatissa et al., 2020). This need to be considered while adjusting salt iodine content in parallel to salt reduction.

The strengths of this study are that: (1) it is population-based; (2) 24-h and SU samples were collected from the same individuals on the same day; (3) around $55 \%$ of the $24-\mathrm{hU}$ samples were collected during weekdays reflecting normal life days; (4) the 24-hU collection is the gold standard measurement of sodium intake and was corrected for incompleteness; (5) several validated equations were used in comparisons; (6) several statistical methods and BA plots were used to assess the best estimates of the SU samples; and (7) multiple established SU equations for adult population were used. The limitations of this study are that $85 \%$ of SU samples were collected in the morning, day variation was not assessed, and SU was collected as part of 24-hU.

\section{CONCLUSIONS}

Salt intake of the Sri Lankan adult population studied is more than double the recommended level and Potassium intake is lower than the recommended level. Extra effort is required to reduce salt and increase potassium intake as planned. This study suggests that SU samples could be an alternative to 24-hU collections for the monitoring of salt in adults using Kawasaki equation, keeping in mind the underestimations. For potassium, the SU samples appear to be less reliable. Although the iodine intake is optimal in this population, it would be advisable to continuously monitor iodine intake using the Zimmerman equation. Monitoring of salt, potassium, and iodine intakes through collection of 24-hU in a subset of SU samples will be important to monitor the salt reduction efforts in Sri Lanka.

\section{Conflicts of interest}

The opinions expressed are those of the authors and do not necessarily reflect the views of the institutions that they are affiliated with. The Authors declare that there is no conflict of interest. Regular budget was used from the Ministry of Health for this study and no funds were received from any funding agency in the commercial, or not-for-profit sectors.

\section{Acknowledgement}

The authors thank staff of Department of Nutrition, Medical Research Institute, Ministry of Health, Sri Lanka for conducting the national survey and all the participants of the study. The authors also thank Dr Nilmini Hemachandra, WHO Colombo; Dr Jacqui Webster, George Institute, Sydney, Australia; Dr Champika Wickramasingha and Dr Lakmini Tilakaratna from Ministry of health, Colombo for the support and Dr M. Zimmerman and A. Leonie for supporting with iodine equations. 


\section{REFERENCES}

Brown I.J., Dyer A.R., Chan Q., Cogswell M.E., Ueshima H., Stamler J. \& Elliott P. (2013). Estimating 24-hour urinary sodium excretion from casual urinary sodium concentrations in Western populations: the INTERSALT study. American Journal of Epidemiology 177(11):118092.

DOI: https://doi.org/10.1093/aje/kwt066

Campbell N.R.C., Dary O., Cappuccio F.P., Neufeld L.M., Harding K.B. \& Zimmermann M.B. (2012). Need for coordinated programs to improve global health by optimizing salt and iodine intake. Pan American Journal of Public Health 32(4): 281-286. DOI: https://doi.org/10.1590/S1020-49892012001000006

Central Bank of Sri Lanka (CBS). (2019). Economic and Social Statistics of Sri Lanka. Statistics Department, Central Bank of Sri Lanka, Colombo, Sri Lanka.

Charlton K.E., Ware L.J., Baumgartner J., Cockeran M., Schutte A.E., Naidoo N. \& Kowal P. (2018). Iodine status assessment in South African adults according to spot urinary iodine c concentrations, prediction equations, and measured 24-h iodine excretion. Nutrients 10(6): 736. DOI: https://doi.org/10.3390/nu10060736

Elliott P., StamlerJ., Nichols R., Dyer A.R., Stamler R., Kesteloot H. \& Marmot M. (1996). Intersalt revisited: further analyses of 24-hour sodium excretion and blood pressure within and across populations. British Medical Journal 312(7041): 1249-1253.

DOI: https://doi.org/10.1136/bmj.312.7041.1249

Gamage A.U., Seneviratna R.D. \& Hanna F.S. (2017). Salt intake, blood pressure, and socioeconomic disparities among government employees in Sri Lanka: a cross-sectional study. Journal of Public Health Policy 38(3):327-344. DOI: https://doi.org/10.1057/s41271-017-0073-0

He F.J., Li J. \& Macgregor G.A. (2013). Effect of longerterm modest salt reduction on blood pressure: Cochrane systematic review and meta-analysis of randomised trials. British Medical Journal 346(f1325): 1-15. DOI: https://doi.org/10.1136/bmj.f1325

Huang L., Crino M., Wu J.H., Woodward M., Barzi F., Land M., McLean R., Webster J., Enkhtungalag B. \& Neal B. (2016). Mean population salt intake estimated from 24-h urine samples and spot urine samples: a systematic review and meta-analysis. International Journal of Epidemiology 45(1): 239-250. DOI: https://doi.org/10.1093/ije/dyv313

Institute of Medicine (IOM). (2001). Dietary Reference Intakes for Vitamin A, Vitamin K, Arsenic, Boron, Chromium, Copper, Iodine, Iron, Manganese, Molybdenum, Nickel, Silicon, Vanadium, and Zinc: A Report of The Panel on Micronutrients. Food and Nutrition Board, National Academy Press, Washington DC, USA.

Jayatissa R., Fernando D.N. \& De Silva H. (2017). National Nutrition and Micronutrient Survey of Pregnant Women in Sri Lanka-2015. Medical Research Institute, UNICEF and World Food Programme. Colombo, Sri Lanka.
Jayatissa R., Yamori Y., De Silva A.H., Mori M., De Silva P. \& De Silva K.H. (2020). Estimation of salt intake, potassium intake and sodium-to-potassium ratio by 24-hour urinary excretion: an urban rural study in Sri Lanka. Preprint. DOI: https://doi.org/10.1101/2020.04.17.20068833

Jayatissa R., Gorstein J., Okosieme O.E., Lazarus J.H. \& Premawardhana L.D. (2020). Stable iodine nutrition during two decades of continuous universal salt iodisation in Sri Lanka. Nutrients 12(4): 1109.

DOI: https://doi.org/10.3390/nu12041109

Jianwei X., Wang M., Chen Y., Zhen B., Li J., Luan W., Ning F., Liu H., Ma J. \& Ma G. (2014). Estimation of salt intake by 24-hour urinary sodium excretion: a cross-sectional study in Yantai, China. BMC Public Health 14: 136.

DOI: https://doi.org/10.1186/1471-2458-14-136

Johner S., Boeing H., Thamm M. \& Remer T. (2015). Urinary 24-h creatinine excretion in adults and its use as a simple tool for the estimation of daily urinary analyte excretion from analyte/creatinine ratios in populations. European Journal of Clinical Nutrition 69(12): 1336-1343.

DOI: https://doi.org/10.1038/ejcn.2015.121

Kawasaki T., Itoh K., Uezono K. \& Sasaki H. (1993). A simple method for estimating $24 \mathrm{~h}$ urinary sodium and potassium excretion from second morning voiding urine specimen in adults. Clinical Experiment in Pharmacology and Physiology 20(1): 7-14. DOI: https://doi.org/10.1111/j.1440-1681.1993.tb01496.x

Mage D.T., Allen R.H. \& Kodali A. (2008). Creatinine corrections for estimating children's and adult's pesticide intake doses in equilibrium with urinary pesticide and creatinine concentrations. Journal of Expo Science Environment Epidemiology 18(4): 360-368. DOI: https://doi.org/10.1038/sj.jes.7500614

Mahadeva K. \& Karunanayake E.H. (1970). Salt intake in Ceylon. British Journal of Nutrition 24(3): 811-814. DOI: https://doi.org/10.1079/BJN19700084

Mill J.G., Rodrigues S.L., Baldo M.P., Malta D.C. \& Szwarcwald C.L. (2015). Validation study of the Tanaka and Kawasaki equations to estimate the daily sodium excretion by a spot urine sample. Brazilian Journal of Epidemiology 18(2): 224-237.

DOI: https://doi.org/10.1590/1980-5497201500060020

Ministry of Health, Nutrition and Indigenous Medicine (2018). National Salt Reduction Strategy 2018-2022. Ministry of Health, Nutrition and Indigenous Medicine. Colombo, Sri Lanka.

Ministry of Health (2020). Annual Health Bulletin 2017. Ministry of health. Colombo. Available at http://www. health.gov.lk/moh_final/english/others.php?pid $=110$

Pan American Health Organisation (PAHO). (2010). Protocol for Population Level Sodium Determination in 24-hour Urine Samples. PAHO, Washington, USA.

Perrine C.G., Cogswell M.E., Swanson C.A., Sullivan K.M., Chen T., Carriquiry A., Dodd K.W., Caldwell K.L. \& Wang C. (2014). Comparison of population iodine estimates from 24-hour urine and timed-spot urine samples. Thyroid 24(4): 748-757.

DOI: https://doi.org/10.1089/thy.2013.0404 
Santos J.V. et al. (11 authors) (2019). Estimating mean population salt intake in Fiji and Samoa using spot urine samples. Nutrients 18(55): 2-9. DOI: https://doi.org/10.1186/s12937-019-0484-9

Tanaka T., Okamura T., Miura K., Kadowaki T., Ueshima H., Nakagawa H. \& Hashimoto T. (2002). A simple method to estimate populational 24-h urinary sodium and potassium excretion using a casual urine specimen. Journal of Human Hypertension 16(2): 97-103. DOI: https://doi.org/10.1038/sj.jhh.1001307

Umesawa M. et al. (13 authors) (2008). Relations between dietary sodium and potassium intakes and mortality from cardiovascular disease: the Japan Collaborative Cohort Study for Evaluation of Cancer Risks. American Journal Clinical Nutrition 88(1): 195-202. DOI: https://doi.org/10.1093/ajcn/88.1.195

UNICEF (2019). Guidance on the Monitoring of Salt Iodization Programmes and Determination of Population Iodine Status. United Nations International Children's Emergency Fund, New York, USA.

Whitton C., Gay G.M., Lim R.B., Tan L.W., Lim W.Y. \& Van Dam R.M. (2016). Evaluation of equations for predicting 24-hour urinary sodium excretion from casual urine samples in Asian adults. The Journal of Nutrition 146(8): 1609-1615. DOI: https://doi.org/10.3945/jn.116.232108

World Health Organization (WHO) (2010). Creating an Enabling Environment for Population-Based salt Reduction Strategies: Report of a Joint Technical Meeting held by WHO and the Food Standards Agency. World Health
Organization, Geneva, Switzerland.

World Health Organization (WHO) (2012a). Guideline: Sodium Intake for Adults and Children. World Health Organization, Geneva, Switzerland.

World Health Organization (WHO) (2012b). Guideline: Potassium Intake for Adults and Children. World Health Organization, Geneva, Switzerland.

World Health Organization (WHO) (2013). Global Action Plan for the Prevention and Control of Noncommunicable Diseases. World Health Organization, Geneva, Switzerland. World Health Organization (WHO) (2017a). Tackling NCDs: 'best buys' and Other Recommended Interventions for the Prevention and Control of Noncommunicable Diseases. World Health Organization, Geneva, Switzerland.

World Health Organization (WHO) (2017b). The updated Appendix 3 of the WHO Global NCD Action Plan 20132020. World Health Organization, Geneva, Switzerland.

World Health Organization (WHO) (2018). How to Obtain Measures of Population-level Sodium Intake in 24-hour Urine Samples. WHO Regional Office for the Eastern Mediterranean. Cairo, Egypt.

Xu J., Zhang J., Liu M., Bai y., Guo X., Dong J. \& Xu A. (2020). Estimating 24-hour sodium excretion from spot urine samples in Chinese adults: can spot urine substitute 24-hour urine samples? Nutrients 12(3): 798. DOI: https://doi.org/10.3390/nu12030798

Zimmermann M.B. \& Andersson M. (2012). Assessment of iodine nutrition in populations: past, present, and future. Nutrition Reviews 70(10): 553-570. DOI: https://doi.org/10.1111/j.1753-4887.2012.00528.x 